\title{
Pregnancy in Patients With Low Back Pain
}

\author{
Afsoun Seddighi $^{\circledR}$, Amir Saied Seddighi ${ }^{\circledR}$, Shiva Jamshidi ${ }^{1}$, Hesam Rahimi Baghdashti ${ }^{1}$ \\ ${ }^{1}$ Functional Neurosurgery Research Center, Shohada Tajrish Comprehensive Neurosurgical Center of Excellence, Shahid \\ Beheshti University of Medical Sciences, Tehran, Iran
}

\begin{abstract}
Pregnancy-related lumbopelvic pain has been a serious and common problem since ancient time. The present review article focuses on terminology, types, clinical presentation, and management of these problems.

There are two entities regarding pregnancy-related lumbopelvic pain: pelvic girdle pain (PGP), and pregnancy-related low back pain (LBP). There are multiple mechanisms behind these disabilities.

Age, multiparty, heavy weight lifting, hard physical activity, previous LBP, and low education increase the prevalence. About one-half of women with pregnancy-related lumbopelvic pain have PGP, one-third LBP, and one-sixth have both conditions. Overall, the literature reveals that PGP deserves serious attention from the clinical and economic standpoints.

Keywords: Pregnancy; Pelvic Girdle Pain; Delivery; Cesarean Section; Low Back Pain.
\end{abstract}

*Correspondence to

Amir Saied Seddighi, Associate

Prof of Neurosurgery, Functional Neurosurgery Research Center, Shohada Tajrish Comprehensive Neurosurgical Center of Excellence, Shahid Beheshti University of Medical Sciences, Tehran, Iran. Tel: +98 2122724212,

Email: a_sedighi@sbmu.ac.ir

Published online August 31, 2019

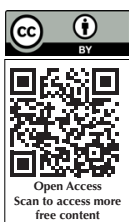

\section{Introduction}

Low back pain (LBP) is a common complaint in pregnant women almost $50 \%$ of pregnant women experience LBP during their pregnancy. ${ }^{1}$

It can cause severe effects on daily life activities and even can alter the psychological status of the patients. ${ }^{2}$

LBP in pregnancy can classify into lumbar pain (LP) and Pelvic girdle pain (PGP). Walde described the differences between PGP and LP in $1962 .^{3}$

LBP begins mostly between fifth and seventh month of gestational age. However, it can occur at any time. ${ }^{4}$ The characteristics of LBP in pregnant women is not different from the normal population. The location is under the 12 th rib up to the level of the inferior gluteal fold. LBP can cause tenderness over paravertebral muscles. ${ }^{5}$ LBP aggravates with some posture and aggravates in prolong sitting, and it is more common in the postpartum period. It seems that it is less disabling than PGP. ${ }^{2}$

PGP is common during pregnancy and postpartum period and approximately 4 times as prevalent as LBP. ${ }^{6}$ It presents as deep, stabbing, unilateral or bilateral, recurrent or continuous pain, presenting between the post iliac crest and the gluteal fold, possibly radiating to the posterolateral thigh, to the knee and calf, but not to the lower extremities. PGP is more intense during pregnancy than during the postpartum period. ${ }^{5}$

\section{Etiology}

The primary etiology of LBP during pregnancy has not identified. However, several mechanisms have proposed. These mechanisms are mechanical, hormonal, muscular, vascular, sciatica and osteitis condensans ilii. ${ }^{5}$

\section{Mechanical}

In most pregnancies, about 10-12 kg weight gain expected, and the center of gravity of the body shifts forward. In order to correct it, the pelvis has to tilt forward. So it causes an increase in the natural inward curve of the lumbar region. This phenomenon increases the lengths of the paravertebral muscles, so they become weaker. Moreover, the stability of the pelvis and lower part of the body decreases. ${ }^{7-10}$

On the other hand, weight gain also causes extra pressure on the spine that leads to severe back pain. ${ }^{11}$

\section{Hormonal}

Many pregnant women experience back pains during the first trimester of their pregnancy, so increased mechanical pressure may not be responsible. This pain may induce by a hormone called "Relaxin," which its secretion increases ten times during pregnancy. This hormone causes ligamentous laxity that reduces the stability of the pelvic region and leads to instability pain. However, the 
association between circulating levels of Relaxin and LBP in pregnancy is under debate. ${ }^{6,7,11,13,14}$

\section{Muscular}

During pregnancy, the pressure on the pelvic floor has increased due to the increasing size of the fetus. The abdominal muscles lengths are increased to accommodate the growing baby. This reduces the power to provide stability to the pelvis. ${ }^{7,11,15}$

\section{Venous}

Another theory suggests that LBP during pregnancy, which worsens at night, maybe the consequence of the expanding uterus putting pressure on the vena cava causing venous congestion in the pelvis and the lumbar spine. $^{11}$

\section{Sciatica}

Sciatica is a rather rare clinical entity of LBP during pregnancy, appearing in only $1 \%$ of women. ${ }^{16}$

\section{Osteitis Condensans Illii}

Osteitis condensans ilii is benign sclerosis of the ileum adjacent to the sacroiliac joint, but it does not involve sacroiliac joint. Typically it is symmetrical and bilateral. The underlying etiology is not clear, but it seems that mechanical stress across the SI joint may cause this condition. It is usually asymptomatic, but it may cause lower back pain, especially in pregnant women. In cases with refractory LBP in the postpartum period, this etiology must be considered. ${ }^{16}$

\section{Diagnosis}

The management of pain individualized in every case, and early diagnosis is necessary. So a good history and complete examination must be done. ${ }^{17}$

Several diagnostic tests have been developed to differentiate PGP from LBP. Posterior pelvic provocation test (PPPT) was proposed by Ostgaard et al, which performed with the patient lying in the supine position and the hip at 90 degrees of flexion. Then pressure is applied at the knee along the axis of the femur, while the pelvis stabilized at contralateral anterior iliac spine. The ipsilateral pain considered a positive result of the test. This test has a positive predictive value of 0.912 . PPPT is positive in patients suffering from PGP, but it is negative in case of LP. ${ }^{2,3,5,18}$ To Differentiate PGP from
LBP, Patrick-Faber test and SLRT may also help. SLRT is usually positive in LP and negative in PGP. Patrick-Faber test is vice versa. ${ }^{6,7}$

Van de Pol made a questionnaire to evaluate the ability to do normal household activities in pregnant women suffering LBP. This questionnaire indicates pregnancy mobility index. ${ }^{19}$ In order to measure disability caused by LBP, Quebec back pain disability scale can be used. ${ }^{11}$

\section{Risk Factors}

The most common causes of LBP in pregnancy are listed below. Pelvic trauma, ${ }^{20}$ chronic LBP, past medical history of LBP in a previous pregnancy, ${ }^{21}$ Gravidity (total number of pregnancies), ${ }^{22}$ and history of LBP during menstruation. ${ }^{23}$ Also, obesity is controversial, some studies have reported obesity as a risk factor, ${ }^{24}$ while some others did not. ${ }^{6}$ It seems that excessive body weight can be a risk factor for LBP during pregnancy.

\section{Prevention}

An appropriate educational program focusing on good posture in daily activities in companion with exercise can be useful to prevent LBP, ${ }^{25}$ however it may be helpful on LBP, but the effects on PGP has not proven. ${ }^{5}$ Also, women should be advised to use proper seats, cushions, and beds. $^{25}$

Physiotherapy exercises before pregnancy can have a positive effect on preventing LBP. ${ }^{26}$ It has proven that a 12 -week training program during pregnancy is useful in the prevention of LBP, at 36 weeks of pregnancy. The pelvic tilt, backstretch, and hamstring stretch are some examples of these exercises. ${ }^{27}$

\section{Management}

The aims of treating LBP relies on pain management, functional improvement and preventing recurrence or converting into chronic form. ${ }^{6}$

Differentiating LP from PGP is essential for the management of LBP. Conservative management is the treatment of choice for both types of LBP in pregnancy. The basics of LBP management mentioned in Table 1. ${ }^{11,28}$

The best option for delivery in these patients is normal vaginal delivery (NVD). ${ }^{29}$

In a study performed by Rost et al, prevention of extreme maneuvers during delivery and decreasing labor time can reduce the risk of morbidity. ${ }^{30}$

Patients with PGP, symphysis dysfunction, and cases

Table 1. Summary of Basic Management of Back Pain in Pregnancy

\begin{tabular}{ll}
\hline Basic Management of LP & Basic Management of PGP \\
\hline Use footstool for sitting & Use sacral belt \\
Rest during day & Adjust sitting and avoid over flexion of hips and spine \\
Exercising like swimming or pacing & Avoid the activities or sports which exacerbate pain like climbing \\
Avoid sitting for an extended time & Support legs at lying down position with something like a pillow \\
Support back at sitting position with something like a cushion & Rest during pain episodes \\
\hline
\end{tabular}


that suffer from restricted hip movements and impaired gait, may need special attention for management. ${ }^{31,32}$

Patients who have extreme pain or their activities are severely limited, may benefit from induction, however induction risk is usually more than its benefits.

For assisted vaginal delivery, ventouse is favorable in a left lateral position. It is important to lift both legs passively and simultaneously into and out of lithotomy position (when necessary) and keep the legs in a painfree range.

Cesarean section (CS) does not have any benefit for women with LBP. Jain et al reported that when the comfortable birthing position cannot achieve due to severe hip abduction and flexion restriction, CS may be unavoidable. In pregnant women with PGP, the posture of the patient is important. ${ }^{33}$

\section{Epidural Analgesia}

Before performing epidural anesthesia, the pain-free limits of hip abduction and flexion should determined because, after anesthesia, these extreme movements may injure pelvic joints. If the patients are unable to flex in sitting position, they need to aligned with the side of the bed in a side-lying position and even during catheterization of the bladder. ${ }^{6}$

\section{Elective Caesarean Section}

According to the existing literature on patients with PGP, CS has no preference for NVD. The rate of recurrence of PGP and LBP and their severity were not increased significantly after CS compared with NVD. However, in a patient with restricted birthing position CS may be beneficial. $^{6}$

\section{Management in the Postpartum Period}

Hospital stay and morbidity after NVD are more severe in patients with PGP compared to women with LBP, so they need more analgesics, Pelvic supports, and physiotherapy and they need more periods of bed rests. It should noted that breastfeeding will not slow the rate of improvement of clinical symptoms. ${ }^{33}$

PGP usually has a benign course, and the symptoms settle in the majority of cases within the first 3 months of delivery. After 1 year, only $1 \%-2 \%$ of women report significant pain, especially those women who have had more severe pain and spasticity during their pregnancies. ${ }^{6}$

\section{Further Pregnancies}

There is a high risk of recurrence during subsequent pregnancies but if treated early and well managed, may not be as severe. ${ }^{34}$

There is no advantage to leaving a long gap between pregnancies, although some abdominal muscles may not have recovered by 12 months postpartum. ${ }^{35}$

Both LBP and PGP have high rates of reoccurrences in repeated pregnancies. We advocate that at least one- year interval considered between subsequent deliveries. If appropriate conservative treatment and pelvic girdle straightening programs performed correctly, no further interval may be needed. ${ }^{36}$

The Prognosis may be worse inpatient with age more than 29 years, multiparty, prolonged duration of labor, and Lack of education. ${ }^{37}$

\section{Conclusion}

LBP in pregnancy is very common and decreases the quality of life and making pregnancy an awful experience in life. It may present either as axial LBP or PGP. The mainstay of treatment is accurate and early diagnosis and appropriate physical therapy. Careful measures should attempted in the curse of delivery and the postpartum period. Many of these women can safely deliver their babies with normal vaginal deliveries without serious consequences and continue to a normal and healthy life.

\section{Conflict of Interest Disclosures}

The authors declare that they have no conflict of interests.

\section{Ethical Statement}

Not applicable.

\section{References}

1. Fast A, Shapiro D, Ducommun EJ, Friedmann LW, Bouklas T, Floman Y. Low-back pain in pregnancy. Spine (Phila Pa 1976). 1987;12(4):368-71. doi: 10.1097/00007632-19870500000011.

2. Ostgaard HC, Roos-Hansson E, Zetherström G. Regression of back and posterior pelvic pain after pregnancy. Spine (Phila Pa 1976). 1996;21(23):2777-80. doi: 10.1097/00007632$199612010-00013$.

3. Bastiaanssen JM, de Bie RA, Bastiaenen $\mathrm{CH}$, Essed GG, van den Brandt PA. A historical perspective on pregnancyrelated low back and/or pelvic girdle pain. Eur J Obstet Gynecol Reprod Biol. 2005;120(1):3-14. doi: 10.1016/j. ejogrb.2004.11.021.

4. Sehmbi H, D'Souza R, Bhatia A. Low back pain in pregnancy: investigations, management, and role of neuraxial analgesia and anaesthesia: a systematic review. Gynecol Obstet Invest. 2017;82(5):417-36. doi: 10.1159/000471764.

5. Ostgaard HC, Zetherström G, Roos-Hansson E, Svanberg B. Reduction of back and posterior pelvic pain in pregnancy. Spine (Phila Pa 1976). 1994;19(8):894-900. doi: 10.1097/00007632-199404150-00005.

6. Vleeming A, Albert HB, Ostgaard HC, Sturesson B, Stuge B. European guidelines for the diagnosis and treatment of pelvic girdle pain. Eur Spine J. 2008;17(6):794-819. doi: 10.1007/ s00586-008-0602-4.

7. Perkins J, Hammer RL, Loubert PV. Identification and management of pregnancy-related low back pain. J Nurse Midwifery. 1998;43(5):331-40.

8. To WW, Wong MW. Factors associated with back pain symptoms in pregnancy and the persistence of pain 2 years after pregnancy. Acta Obstet Gynecol Scand. 2003;82(12):108691. doi: 10.1046/j.1600-0412.2003.00235.x.

9. Ostgaard HC, Andersson GB, Schultz AB, Miller JA. Influence of some biomechanical factors on low-back pain in pregnancy. Spine (Phila Pa 1976). 1993;18(1):61-5. doi: 10.1097/00007632-199301000-00010.

10. Sandler SE. The management of low back pain in pregnancy. 
Man Ther. 1996;1(4):178-85. doi: 10.1054/math.1996.0266.

11. Sabino J, Grauer JN. Pregnancy and low back pain. Curr Rev Musculoskelet Med. 2008;1(2):137-41. doi: 10.1007/s12178008-9021-8.

12. van Dongen PW, de Boer $M$, Lemmens WA, Theron GB. Hypermobility and peripartum pelvic pain syndrome in pregnant South African women. Eur J Obstet Gynecol Reprod Biol. 1999;84(1):77-82. doi: 10.1016/s0301-2115(98)003078.

13. Stuge B, Hilde G, Vøllestad N. Physical therapy for pregnancyrelated low back and pelvic pain: a systematic review. Acta Obstet Gynecol Scand. 2003;82(11):983-90. doi: 10.1034/j.1600-0412.2003.00125.x.

14. Wedenberg K, Moen B, Norling A. A prospective randomized study comparing acupuncture with physiotherapy for lowback and pelvic pain in pregnancy. Acta Obstet Gynecol Scand. 2000;79(5):331-5.

15. Bewyer KJ, Bewyer DC, Messenger D, Kennedy CM. Pilot data: association between gluteus medius weakness and low back pain during pregnancy. lowa Orthop J. 2009;29:97-9.

16. Vadivelu R, Green TP, Bhatt R. An uncommon cause of back pain in pregnancy. Postgrad Med J. 2005;81(951):65-7. doi: 10.1136/pgmj.2003.015370.

17. Johnson D, Coley S. Back pain in pregnancy. J R Soc Med. 1998;91(6):344. doi: 10.1177/014107689809100624.

18. Ostgaard HC, Zetherström G, Roos-Hansson E. The posterior pelvic pain provocation test in pregnant women. Eur Spine J. 1994;3(5):258-60. doi: 10.1007/bf02226575.

19. van de Pol G, de Leeuw JR, van Brummen HJ, Bruinse HW, Heintz AP, van der Vaart $\mathrm{CH}$. The Pregnancy Mobility Index: a mobility scale during and after pregnancy. Acta Obstet Gynecol Scand. 2006;85(7):786-91. doi: 10.1080/00016340500456373.

20. Mens JM, Damen L, Snijders CJ, Stam HJ. The mechanical effect of a pelvic belt in patients with pregnancy-related pelvic pain. Clin Biomech (Bristol, Avon). 2006;21(2):122-7. doi: 10.1016/j.clinbiomech.2005.08.016.

21. Stapleton DB, MacLennan AH, Kristiansson P. The prevalence of recalled low back pain during and after pregnancy: a South Australian population survey. Aust N Z J Obstet Gynaecol. 2002;42(5):482-5.

22. Ostgaard HC, Andersson GB, Karlsson K. Prevalence of back pain in pregnancy. Spine (Phila Pa 1976). 1991;16(5):549-52. doi: 10.1097/00007632-199105000-00011.

23. Wang SM, Dezinno $P$, Maranets I, Berman MR, Caldwell-Andrews AA, Kain ZN. Low back pain during pregnancy: prevalence, risk factors, and outcomes. Obstet Gynecol. 2004;104(1):65-70. doi: 10.1097/01. AOG.0000129403.54061.0e.

24. Mogren IM. BMI, pain and hyper-mobility are determinants of long-term outcome for women with low back pain and pelvic pain during pregnancy. Eur Spine J. 2006;15(7):1093-102. doi: 10.1007/s00586-005-0004-9.

25. Mørkved S, Salvesen KA, Schei B, Lydersen S, Bø K. Does group training during pregnancy prevent lumbopelvic pain? A randomized clinical trial. Acta Obstet Gynecol Scand. 2007;86(3):276-82. doi: 10.1080/00016340601089651.

26. Owe KM. Exercise before and during pregnancy and reproductive outcomes: a population based cohort study. Oslo: Norwegian School of Sport Sciences; 2011.

27. Mirmolaei ST, Nakhostin Ansari N, Mahmoudi M, Ranjbar F. Efficacy of a physical training program on pregnancy related lumbopelvic pain. International Journal of Women's Health and Reproduction Sciences. 2018;6(2):161-6.

28. Bailey A. Risk factors for low back pain in women: still more questions to be answered. Menopause. 2009;16(1):3-4. doi: 10.1097/gme.0b013e31818e10a7.

29. Mukkannavar P, Desai BR, Mohanty U, Parvatikar V, Karwa D, Daiwajna S. Pelvic girdle pain after childbirth: the impact of mode of delivery. J Back Musculoskelet Rehabil. 2013;26(3):281-90. doi: 10.3233/bmr-130378.

30. Röst CC, Jacqueline J, Kaiser A, Verhagen AP, Koes BW. Prognosis of women with pelvic pain during pregnancy: a long-term follow-up study. Acta Obstet Gynecol Scand. 2006;85(7):771-7. doi: 10.1080/00016340600626982.

31. Robinson HS, Mengshoel AM, Bjelland EK, Vøllestad NK. Pelvic girdle pain, clinical tests and disability in late pregnancy. Man Ther. 2010;15(3):280-5. doi: 10.1016/j. math.2010.01.006.

32. Robinson HS, Mengshoel AM, Veierød MB, Vøllestad N. Pelvic girdle pain: potential risk factors in pregnancy in relation to disability and pain intensity three months postpartum. Man Ther. 2010;15(6):522-8. doi: 10.1016/j.math.2010.05.007.

33. Jain S, Eedarapalli $P$, Jamjute $P$, Sawdy R. Symphysis pubis dysfunction: a practical approach to management. Obstet Gynaecol. 2006;8(3):153-8. doi: 10.1576/ toag.8.3.153.27250.

34. Leadbetter RE, Mawer D, Lindow SW. The development of a scoring system for symphysis pubis dysfunction. J Obstet Gynaecol. 2006;26(1):20-3. doi: 10.1080/01443610500363915.

35. Kanakaris NK, Roberts CS, Giannoudis PV. Pregnancy-related pelvic girdle pain: an update. BMC Med. 2011;9:15. doi: 10.1186/1741-7015-9-15.

36. Leadbetter RE, Mawer D, Lindow SW. The development of a scoring system for symphysis pubis dysfunction. J Obstet Gynaecol. 2006;26(1):20-3. doi: 10.1080/01443610500363915.

37. Albert H, Godskesen M, Westergaard J. Prognosis in four syndromes of pregnancy-related pelvic pain. Acta Obstet Gynecol Scand. 2001;80(6):505-10. 